\title{
Semiotika budaya kemaritiman masyarakat Indonesia pada syair lagu
}

\author{
Daroe Iswatiningsiha, ${ }^{\mathrm{a}}{ }^{*}$, Fauzan $^{\mathrm{b}, 2}$ \\ ab Universitas Muhammadiyah Malang, Jl. Raya Tlogomas 246, Malang, 65144, Indonesia \\ ${ }^{1}$ daroe@umm.ac.id; ${ }^{2}$ fauzan@umm.ac.id \\ * Corresponding Author
}

\begin{tabular}{l} 
INFO ARTIKEL \\
\hline Sejarah Artikel: \\
Diterima: 15 September 2021 \\
Direvisi: 22 September 2021 \\
Disetujui: 26 Oktober 2021 \\
Tersedia Daring: 31 Oktober \\
2021 \\
\hline
\end{tabular}

Kata Kunci:

Budaya kemaritiman

Kajian semiotik

Syair lagu

\begin{abstract}
ABSTRAK
Syair lagu merupakan rangkaian dan tatanan kata indah yang diberi notasi dan dilagukan. Syair lagu memuat simbol-simbol pesan yang hendak disampaikan pencipta kepada pendengarnya. Simbol dalam syair lagu tidak mudah dimengerti dan perlu penafsiran. Pencipta lagu menggunakan simbol verbal pada syair lagu guna mewakili segala hal terkait dengan maksud, harapan, perasaan serta kondisi yang terjadi di lingkungan fisik serta menerjemahkan kehidupan di dunia yang diketahuinya. Untuk memahami sistem tanda yang menggambarkan budaya kemaritiman dalam syair lagu digunakan pendekatan semiotik. Penelitian ini bersifat deskriptif kualitatif, mengkaji bahasa berupa tanda atau simbol dalam syair lagu kemaritiman. Teknik pengumpulan data dengan mendokumentasikan lagu di Museum Musik Indonesia (MMI) di Malang serta eksplorasi di internet. Data berupa aspek kebahasaan yang mengandung sistem tanda budaya kemaritiman dari 14 lagu. Tujuan penelitian mendeskripsikan bentuk penanda dan petanda budaya kemaritiman pada syair lagu dan aspek budaya kemaritiman masyarakat Indonesia. Hasil penelitian ditemukan penanda dan petanda yang menunjukkan budaya kemaritiman pada syair lagu kemaritiman serta empat aspek sistem budaya masyarakat maritim meliputi, sistem mata pencaharian hidup, sistem peralatan hidup dan teknologi, sistem pengetahuan, dan sistem keorganisasian sosial. Lagu-lagu kemaritiman Indonesia merepresentasikan budaya kemaritiman masyarakat pesisir melalui simbol tanda yang ada. Untuk itu, lagu merupakan rekaman budaya masyarakat di masanya.
\end{abstract}

Keywords:

Maritime Culture

Semiotic Studies

Songs

\section{ABSTRACT}

Song verse is a series and arrangement of beautiful words that are noted and performed. The song verse contains symbols of the message that the creator wants to convey to his listener. The symbols in the verse of the song are not easy to understand and need interpretation. The songwriter uses verbal symbols in the song's verse to represent everything related to the intentions, expectations, feelings and conditions that occur in the physical environment and translate life in the world he knows. To understand the sign system that describes maritime culture in song verse, a semiotic approach is used. This research is qualitative descriptive, studying the language in the form of signs or symbols in maritime song verse. Data collection techniques by documenting songs at the Indonesian Music Museum (MMI) in Malang as well as exploration on the internet. Data in the form of language aspects that contain a maritime cultural sign system of 14 songs. The purpose of the study describes the form of markers and signs of maritime culture in song verses and aspects of maritime culture of Indonesian society. The results of the study found markers and signs that show maritime culture in maritime song verses as well as four aspects of the maritime community cultural system including, livelihood system, living equipment system and technology, knowledge system, and social organization system. Indonesian maritime songs represent the maritime 
culture of coastal communities through the symbol of existing signs. For this reason, the song is a recording of the culture of the people of his time. Indonesia pada syair lagu. Satwika : Kajian Ilmu Budaya dan Perubahan Sosial, 5(2), 214-228, https://doi.org/10.22219/satwika.v5i2.18073

\section{Pendahuluan}

Indonesia dikenal sebagai bangsa Bahari yang mampu menaklukkan laut sejak nenek moyang dahulu. Fakta ini dapat dilihat dari sejarah ketangguhan para pelaut, pejuang dan pahlawan yang menjaga wilayah nusantara atau Indonesia, yakni pada kerajaan majapahit dan Sriwijaya. Sebagai negara kepualauan, masyarakat Indonesia bermukim di wilayah-wilayah yang dipisahkan oleh laut dan selat (Rahardja, 2018). Terdapat ribuah gugusan pulau yang dimiliki Indonesia yang membentang pada sepanjang pantai kurang lebih $99.093 \mathrm{~km}^{2}$, yang terpanjang di dunia (Wahid, 2018).

Wilayah Indonesia yang luas terdiri dari daratan dan laut. Wilayah darat lebih kesil daripada lautan yang mencapai $77 \%$. Indonesia memiliki luas kurang lebih 8.300.000 $\mathrm{km}^{2}$ dan sebagian besar merupakan wilayah laut, yakni 6.400 .000 $\mathrm{km}^{2}(77 \%)$. Adapun wilayah laut ini meliputi Zona Ekonomi Eksklusif, laut teritorial, perairan kepulauan, perairan pedalaman, zona tambahan, dan perairan landas kontinen (Kemenko Kemaritiman, 2020). Memahami potensi laut yang dimiilki Indonesia, maka Joko Widodo, Presiden Indonesia ingin memjadikan Indonesia sebagai Poros Maritim guna memperkuat kedaulatan bangsa. Terkait dengan fakta dan kondisi Indonesia sebagai bangsa yang memiliki banyak pulau, maka upaya menjaga wilayah perairan penting dilakukan oleh semua warga Indonesia dan hal ini dapat dikenalkan sejak dini melalui lagulagu kemaritiman. Lagu-lagu kemaritiman memuat sejarah/geneologi yang memberikan ilustrasi masyarakat pelaut dengan segala perjuangan dan keberanian di tengah samudra (Darmoko, 2019). Pendidikan saat ini kurang mengenalkan lagu-lagu kemaritiman seperti pada anakanak seperti dahulu dengan lagu yang terkenal "Nenek Moyangku Seorang pelaut", ciptaan ibu Soed. Lagu-lagu yang mengungkap laut, samudera dan kehidupannya lebih banyak diciptakan untuk orang dewasa.

Pendidikan merupakan wahana dalam mengenalkan, memahamankan dan menumbuhkan kecintaan generasi muda untuk menjaga laut beserta sumberdaya yang ada di dalamnya melalui karya-karya yang diciptakan, baik dalam bidang seni sastra, musik, tarian, lukis, seni rupa yang lainnya. Sudah banyak karya-karya sastra yang menggambarkan kemaritiman, seperti novel Tenggelamnya kapal Van Der Wijk (Hamka, 1962), Novel Arus balik (Toer, 1995), Gadis Pantai (Toer, 1987), dan yang lain. Dalam puisi-puisinya, Zawawi Imron menjandikan laut sebagai muatan kehidupan, sebagai akhir dari kehidupan, Bantalku Ombak Selimutku Angin (2000) dan yang lain. Banyak juga para peserta didik yang mengangkat tema laut dan kehidupan di dalamnya sebagai karya puisi. Bentuk lain dalam membangu rasa cinta terhadap laut dan kehidupan di sekitarnya dengan nyayian. Syair lagu pada dasarrnya sebuah puisi yang diberi not-not dan nada yang dinyayikan (Dewi, et. al., 2018; Harnia, et. al., 2021; Wiradharma, et. al., 2017). Sebuah lagu yang menggambarkan kondisi kemaritiman masyarakat Inonesia sejak nenek moyang terekam dalam syair lagu 
karya Ibu Sud yang berjudul "Nenek Moyangku Seorang Pelaut" (1940). Umumnya pada usia kanak-kanak telah diajarkan lagu ini untuk mengenalkan siapa nenek moyang kita. Dalam syair lagu ini digambarkan bahwa nenek moyang bangsa Indonesia adalah seorang pelaut yang pemberani, menjelajah mangarungi samudera luas, pemberani menerjang ombak dan badai yang berlayar. seperti pada syair berikut.

\section{Nenek moyangku seorang pelaut Gemar mengarung luas samudera Menerjang ombak tiada takut Menempuh badai sudah biasa}

Dalam syair lagu umumnya memuat pesan, nilai, semangat, perasaan, kemauan, dan yang lainnya dan hal ini penting dikenalkan pada anak sejak usia dini (Fuad \& Musa, 2017). Hal ini sebagaimana syair lagu "Nenek Moyangku Seorang Pelaut" yang menggambarkan semangat, keberanian, kemauan, dari seorang pelaut.

Karakter nasionalis sebagai bangsa Bahari penting dikenalkan dan dikuatkan kepada generasi muda guna menjaga kedaulatan dan kesatuan Indonesia. Upaya tersebut sebagai salah satu pembentukan karakter nasionalis generasi muda terhadap sejarah, tradisi, semangat, dan ketangguhan Indonesia sebagai negara maritim. Adapun upaya mengenalkan dan membangun karakter generasi muda melalui syair lagu yang diciptakan penulis lagu atau yang dinyanyikan sebagai ekspresi dan penghargaan sesuia masanya. Syair lagu merupakan ekspresi estetis yang mengomunikasikan pengetahuan, trasdisi, keindahan Indonesia sebagai kumpulan pulau, samudera, laut, dengan segala kekayaannya. Hingga pada akhirnya sikap kecintaan terhadap bangsa ini menjadi sebuah perilaku yang melekat dan teraktualisai dalam pikiran dan tindakan (Darmoko, 2019; Kusumawati, 2013).

Aspek budaya dalam sebuah lagu dinyatakan dalam ekspresi kebahasaan, baik secara tersirat maupun tersurat. Untuk memahami budaya masyarakat maritim dapat dikenali dari sistem tanda bahasa yang merujuk pada objek yang dimaksud berdasarkan hasil interpretan yang berelasi antara keduanya. Tanda dalam kajian semiotik yang mencoba memahami budaya masyarakat bahari menurut Barthers dapat dilakukan dengan memaknai hal-hal yang terkait pada objeknya. Dalam hal ini objek bukan sebatas menyimpan informasi, namun berupaya mengomunikasikannya kepada siapapun. Dalam hal ini penafsir, yakni seseorang yang telah memiliki serangkaian konsep dapat menjelaskan makna dari petanda yang dihadirkannya. Sobur (2002) menyatakan bahwa penanda yang mewakili konsep dan makna dapat digambarkan melalui lambang, ikon dan indek. Dengan memperhatikan tanda kebahasaan melalui syair lagu dapat dikenali budaya kemaritiman masyarakat Indonesia berdasarkan sistem sosial, nilai nilai budaya yang berlau, sistem mata pencaharian hidup serta sistem pengetahuan yang menjadi pedomann dalam bersosialisasi dan berinteraksi. Sistem nilai yang menjadi landasan hidup dan merupakan abstraksi dari nilai yang dijunjung tinggi setiap masyarakat tidak sama dan bahkan bertentangan. Kluckhohn (dalam Pasaribu, 2015) bahwa perbedaan sistem nilai dalam setiap masyarakat dianggap hal sudah biasa, namun orientasi nilai yang dianggap sebagai nilai budaya secara universal memiliki peesamaan, yakni hakikat hidupa manusia, hakinat, karya, hakikat waktu, hakikat alam, dan hakikat hubungan manusia.

Untuk itu, aspek kebudayaan pada masyarakat maritim sangat ditentukan bagaimana masyarakat dalam menyikapi kehidupan di lingkungan pesisir yang yang panas, alam yang penuh tantangan dan perubahan yang tidak dapat diprediksikan. Namun masyararakat nelayan memiliki sistem sosial yang erat dan terintegrasi satu dengan yang lain atas dasar kesepakatan bersama (Hairudin \& Wahyuni, 2019). Budaya yang menjunjung nilai-nilai hidup pada masyarakat maririm lebih mengedepankan pada keberanian, 
kecakapan, keterampilan menghadapi berbagai masalah dan tantangan, serta mampu membaca tanda-tanda kehidupan terlebih yang berkaitan dengan alam (Kambey et. al., 2020).

Kekuatan yang dimiliki masyarakat maritim dapat ditelusuri dari penanda verbal dalam syair lagu kemaritiman. Selanjutnya pemahaman masyarakat, khussusnya generasi muda dapat dimanfaatkan sebagai penguatan karakter. Penguatan karakter yang didengungkan oleh Presiden Jokowi terkait dengan cita-cita bangsa menjadi negara yang tangguh baik di darat maupun di laut dari berbagai ancaman yang mengganggu kedaulatan NKRI (Negara Kesatuan Republik Indonesia) (Ismail \& Kartika, (2019); Harnoko, (2016); Darmoko (2019); Hal ini mengingat Indonesia sebagai negara kepulauan yang memiliki keragaman budaya yang rawan terjadi konflik akibat perbedaan atau kesenjangan yang ada. Lebih kanjut hasil pengetahuan bersama tentang budaya kemaritiman dapat dimanfaatkan sebagai materi pendidikan serta kebijakan bangsa dalam mewujudkan pembangunan Indonesia sebagai Poros Maritim Dunia. Hal ini sesungguhnya merupakan pernyataan visi geopolitik dan sebagai penegasan manifestasi tujuan nasional, sekaligus sebagai momentum penerapan strategi pembangunan nasional berbasiskan atau berorientasi kemaritiman. Upaya penguatan ekonomi maritim dilakukan melalui pembenahan di hulu pembangunan industri dan sistem logistik secara nasional (Harnoko 2016). Memahami pentingnya mengenali dan menyebarkan informasi sejarah peradaban Indonesia sebagai negara maritim, maka penting dilakukan penelitian dalam melestarikan budaya kemaritiman melalui syair lagu dengan menggunakan pendekatan semiotik. Pendekatan semiotik berusaha mengenali sistem tanda kebahasaan-penanda (signifier) dan petanda (signified)_guna memahami makna yang dihadirkannya (Sobur, 2002). Untuk itu, permasalahan yang ingin ditemukan dalam penelitian ini adalah bentuk tanda yang menggambarkan budaya kemaritiman bangsa Indonesia melalui syair lagu serta makna tanda dalam mengenali budaya kemaritiman pada bangsa Indonesia.

Budaya atau kebudayaan yang hadir di dalam masyarakat merupakan suatu sistem yang mengatur tingkah laku manusia secara individual yang diturunkan dalam kehidupan bersosial. Dalam kehidupan bermasyarakat, tata aturan diberlakukan secara konvensional yang diikuti bersama dan menjadi sebuah tradisi dan adat istiadat yang mengatur anggota masyarakat di dalamnya, tidak terkecuali keluarga (Wasono (2017); Udu (2017). Bahasa turut menentukan identitas dan entitas budaya sebuah bangsa. Di dalam masyarakat maritime, bahasa menyimpan nilai kemasyarakatan, penyebaran kebudayaan masyarakat maritim, alat penamaan dan pelabelan, serta sebagai pemerkaya budaya bangsa (Oktavianus, 2019).

Syawaludin (2017) memandang bahwa dalam kehidupan bermasyarakat secara tradisional lebih bersifat mekanis, yang cebderung dipersatukan oleh adanya kesamaan cara hidup termasuk teknologi dan bentuk organisasi ekonomi, pola-pola menetap, bentuk pengelompokan sosial dan pengelompokan politik, kepercayaan dan praktek keagamaan dan seterusnya. Budaya masyarakat tersebut sifatnya menetap dan secara turun temurun akan dipindahkan pada generasi selanjutnya melalui proses pembelajaran, latihan dan disesuaikan dengan kondisi lingkungan yang cocok guna mempertahankan hidup. Geertz mengemukakan bahwa bahwa budaya merupakan sistem makna dan simbol yang memuat pengertian yang memungkinkan individu-individu untuk mendefinisikan dunianya dalam menyatakan perasaan dan memberikan penilaian. Selanjutnya hasil pemaknaan tersebut ditransmisikan secara historis, diwujudkan dalam bentuk simbolik melalui sarana guna mengomunikasikan, mengabdikan dan mengembangkan pengetahuan karena kebudayaan merupakan suatu sistem simbolik yang harus dibaca, diterjemahkan dan diinterpretasikan (Sumarto, 2019). 
Semiotik merupakan kajian bahasa yang menekankan pada penggunaan tanda, simbol, lambang kebahasaan yang mewakilinya. Secara etimologis, Sudjiman \& Van Zoest (1996), menyampaikan istilah semiotika berasal dari kata Yunani "semeion" yang berarti tanda atau "seme" yang berarti penafsir tanda. Sebagai contoh "adanya asap menandai api". Tanda sendiri pada masa itu didefinisikan sebagai sesuatu hal yang menunjuk kepada sesuatu hal yang lain (Sobur, 2009).

Pendekatan semiotika menurut Ferdinand de Saussure mengembangkan dasar-dasar teori linguistik umum. Kekhasan dalam kajian ini terletak pada kenyataan bahwa bahasa sebagai sistem tanda. Menurut Saussure tanda-tanda, khususnya tandatanda kebahasaan, setidak-tidaknya memiliki dua buah karakteristik yaitu bersifat linier dan arbitrer (Budiman, 1999). Adapun pokok pembahasan pada teori Saussure secara prinsip menekankan bahwa bahasa adalah suatu sistem tanda, dan setiap tanda itu tersusun dari dua bagian, yaitu signifier (penanda) dan signified (petanda) (Fanani, 2013). Penanda dan petanda ini merupakan dua hal yang selalu hadir untuk menjelaskan sesuatu yang ingin ditunjukkan. Penanda (signifier) dalam pengertian Saussure, oleh Barthers diartikan sebagai ekspresision (ungkapan) dan petanda sebagai content (isi). Selanjutnya keduanya dihubungkan oleh relasi yang ditentukan berdasarkan konteks penggunaan untuk mendapatkan makna.

Konteks sosial dan budaya turut memberikan pemaknaan terhadap rujukan petanda dan penanda guna menjelaskan isi tanda (sign) yang dihadirkan apakah berupa simbol-simbol atau tanda yang disepakati atau yang bersifat arbitrer. Teori tanda atau semiotik ini selanjutnya dapat digunakan untuk menjelaskan simbol-simbol yang terdapat pada syair lagu yang mengandung budaya kemaritiman pada masyarakat Indonesia yang sudah dikenal sejak lama. Budaya apa yang yang dapat digali melalui syair lagu yang pernah tercipta dan dinyanyikan/dipopulerkan masayarakat menggambarkan kehidupan kelautan, pantai, yang bersifat pola pikir, sikap, tindakan, sistem kekerabatan, serta aspek kebudayaan lain.

Kajian tentang kemaritiman sudah pernah dilakukan oleh beberapa peneliti yang membahas tentang potensi, sumber daya, dan peran Indonesia sebagai negara maritim (Ismail, et. al., 2019; Janawi, 2018; Wibowo, 2017). Penelitian yang mengangkat budaya masyarakat pesisir dan kearifan lokal kemaritiman dilakukan oleh Darmoko (2019), Touwe (2020), Hairudin \& Wahyuni (2019), dan Wasono (2017). Dalam beberapa penelitian tersebut menggambarkan bahwa masyarakat pesisir berada pada kondisi yang memprihatinkan karena peralatan kerja seperti kapal masih menyewa dan pendapatan yang diperolehnya hanya cukup untuk memenuhi kebutuhan yang pas-pasan saja. Mereka bekerja melaut juga sangat ditentukan oleh kondisi alam dan penuh perjuangan saat berada di lautan. Penelitian yang mengaitkan kemaritiman dengan pendidikan dilakukan oleh Fuad \& Musa (2017). Dalam penelitian menyakinkan bahwa kanak-kanak pada usia dini penting mendapatkan pembelajaran tematik yang memperkenalkan potensi kemaritiman di Indonesia. Hal ini akan menumbuhkan kecintaan, rasa bangga, dan sikap menjaga kepulauan Indonesia. Adapun beberapa penelitian tentang semiotic juga banyak dikaji dan dilakukan. Namun demikian, penelitian yang mengaitkan sistem tanda denga syair lagu kemaritiman belum dikaji. Untuk itu, penelitian tentang Kajian semiotik budaya kemaritiman pada masyarakat Indonesia melalui syair lagu penting dilakukan.

Adapun permasalahan penelitian difokuskan pada budaya kemaritiman yang direpresentasikan oleh sistem tanda melalui pendekatan semiotik pemikiran Ferdinand de Saussue. Sistem tanda ditemukan pada beberapa syair lagu kemaritiman yang dicipta dan dipopulerkan di Indonesia hingga saat ini untuk merekam aspek kebudayaan kemaritiman yang ada di dalamnya. Terdapat tiga tujuan yang ingin 
ditemukan dalam penelitian ini terkait dengan budaya kemaritiman yang digambarkan dalam syair lagu yang populerkan oleh penyanyi Indonesia, meliputi (1) bentuk-bentuk simbol-simbol berupa penanda dan petanda yang menggambarkan budaya kemaritiman pada syair lagu dan (2) Budaya kemaritiman masyarakat Indonesia dalam syair lagu.

\section{Metode}

Penelitian ini bersifat deskriptif kualitatif, yakni bertujuan mendeskripsikan hasil temuan berupa simbol-simbol kebahasaan yang menggambarkan budaya kemaritiman (Creswell, 2010). Aspek budaya yang digali mencakup enam komponen dalam konsep Koentjaraningrat dan Kluckhohn. Hal ini dikarenakan, syair lagu sebagai objek kajian hanya ditujukan pada lagu-lagu berbahasa Indonesia dan berbahasa Jawa yang menggambarkan aspek kemaritiman. Penelitian ini menggunakan data bahasa berupa bahasa pada lagu-lagu kemaritiman yang dinyatakan dalam ekspresi tanda atau simbol, makna, dan konteks budaya kemaritiman yang mencakup (a) sistem peralatan hidup dan teknologi, (b) sistem mata pencaharian, (c) sistem pengetahuan, (d) sistem kemasyarakatan dan organisasi sosial, (e) kesenian, dan (f) sistem religi, (g) nilai-nilai sosial dan sistem budaya.

Berdasarkan lagu-lagu kemaritiman yang menggambarkan budaya masyarakat maritim, maka peneliti mengidentifikasi syairnya berdasarkan ketiga fokus yang dikaji yakni bentuk simbol yang mereferensi pada budaya maritim, makna dan konteks yang membangunnya. Sumber data berupa syair lagu-lagu yang dieksplorasi peneliti dari kaset yang tersimpan di Museum Musik Indonesia (MMI) di Malang, YouTube, dan sumber internet.

Peneliti telah berkunjung ke MMI untuk mengobservasi koleksi lagu dan melakukan wawancara kepada ketua MMI untuk lagu kemaritiman yang dimiliki. Dari hasil wawancara diperoleh 30 judul lagu beserta pencipta dan penyanyinya. Setelah ditelaah berdasarkan aspek semiotik, maka didadaptkan 14 lagu. Adapun rincian lagu berikut ini: 1) Perahu Retak (Franky Sahilatua); 2) Tanjung Perak (Waldjinah); 3) Gulagalugu (Leo Kristi); 4) Rayuan Pulau Kelapa (Ismail Mardzuki); 5) Kolam susu (Koes Plus); 6) Tampomas (Iwan Fals); 7) Telur Bayur (Erni Johan); 8) Tak Biru Lagi Lautku (Iwan Fals); 9) Nelayan (Iwan Fals); 10) Nyanyian Pantai (Leo Kristi); 11) Nelayan Tua (bimbo); 12) Lenggak Lenggok Badai Lautku (Leo Kristi); 13) Balada pelaut (titiek puspa); dan 14 Nenek Moyangku Seorang Pelaut.

Dari empat belas lagu tersebut selanjutnya dianalalisis dengan teknik deskriptif dengan pendekatan semiotik Saussure dan pengembangannya Barthers. Pendekatan semiotika Saussure menekankan tanda dalam konteks komunikasi manusia dengan melakukan pemilahan antara signifier (penanda) dan signified (petanda). Eksistensi semiotika Saussure adalah relasi antara penanda dan petanda berdasarkan konvensi, yang biasa disebut dengan signifikasi. Adapun kajian tanda pada Barthers yang dikembangkan dari turunan Saussure pada pengembangan makna konotasi (Haryadi, 2016).

Teknik analisis data menggunakan analisis interpretasi teks yang dilakukan dengan mengidentifikasi keseluruhan syair lagu yang memuatkan budaya kemaritiman. Selanjutnya mengelompokan aspek budaya kemaritiman yang digambarkan serta menafsirkan tanda-tanda berdasarkan makna dalam mengungkap signifier dan signified. Terkahir, peneliti menyimpulkan budaya kemaritiman objek dan pemaknaannya berdasarkan kerelasian yang terkandung melalui syair lagu yang diciptakan dan yang dipopulerkan di Indonesia

\section{Hasil dan Pembahasan}

\subsection{Bentuk Penanda dan Petanda pada Syair Lagu Kemaritiman}

Pandangan Saussure terhadap kajian tanda (sign) mencakup dua unsur, yakni 
adanya penanda (signifier) dan petanda (signified). Keduanya dapat ditemukan dalam konteks komunikasi yang dituangkan dalam syair lagu kemaritiman. Bentuk penanda yang yang merepresentasikan kemaritiman berupa frase dan klausa tampak pada tabel 1 berikut.

Tabel 1. Bentuk penanda dan petanda dalam syair lagu kemaritiman

\begin{tabular}{|c|c|}
\hline Penanda (signifier) & Petanda (Signified) \\
\hline Perahu nelayan & Perahu yang sederhana \\
\hline Perahu layar & $\begin{array}{c}\text { Perahu yang } \\
\text { menggunakan layar } \\
\text { sebagai penggerak }\end{array}$ \\
\hline $\begin{array}{c}\text { Perahu memecah } \\
\text { ombak }\end{array}$ & $\begin{array}{c}\text { Perahu memecah ombak } \\
\text { di }\end{array}$ \\
\hline $\begin{array}{l}\text { Perahu berayun-ayun di } \\
\text { lautan }\end{array}$ & $\begin{array}{c}\text { Perahu nelayan tampak } \\
\text { kecil di lautan dan mudah } \\
\text { terombang ambing }\end{array}$ \\
\hline Perahu tenggelam & $\begin{array}{l}\text { Perahu nelayan biasanya } \\
\text { tidak dilengkapi dengan } \\
\text { pengaman }\end{array}$ \\
\hline Perahu negeriku & $\begin{array}{c}\text { Perahu nelayan identik } \\
\text { dengan milik sebagian } \\
\text { besar masyarakat } \\
\text { Indonesia }\end{array}$ \\
\hline Perahu bangsaku & $\begin{array}{c}\text { Perahu sederhana dibuat } \\
\text { oleh anak bangsa }\end{array}$ \\
\hline $\begin{array}{l}\text { Perahu menyusuri } \\
\text { gelombang }\end{array}$ & $\begin{array}{c}\text { Perahu kecil dan } \\
\text { sederhana berupaya } \\
\text { menembus gelombang }\end{array}$ \\
\hline Perahu layar melaju & $\begin{array}{c}\text { Perahu berlayar melaju } \\
\text { mengarungi lautan }\end{array}$ \\
\hline $\begin{array}{c}\text { Api menjalar } \\
\text { dari sebuah kapal }\end{array}$ & $\begin{array}{c}\text { Kapal terbakar tanpa } \\
\text { diketahui penyebabnya } \\
\text { dan tidak dilengkapi } \\
\text { dengan pengamanan }\end{array}$ \\
\hline Nelayan tua & $\begin{array}{c}\text { Umumnya yang } \\
\text { serprofesi sebagai nelayan } \\
\text { adalah orang yang sudah } \\
\text { tua }\end{array}$ \\
\hline $\begin{array}{l}\text { (Nelayan) sendiri } \\
\text { mencari nafkah di } \\
\text { samudra }\end{array}$ & $\begin{array}{c}\text { Perahu hanya mempu } \\
\text { memuat seorang } \\
\text { penumpang dan } \\
\text { ditambah hasil tangkapan } \\
\text { ikan }\end{array}$ \\
\hline Nelayan berlayar & $\begin{array}{c}\text { Nelayan menggunakan } \\
\text { perahu berlayar mencari } \\
\text { ikan di lautan }\end{array}$ \\
\hline nelayan ditelah hiu & $\begin{array}{c}\text { Nelayan tak berdaya } \\
\text { menghadapi bahaya di } \\
\text { lautan }\end{array}$ \\
\hline $\begin{array}{c}\text { Berbondong-bondong } \\
\text { nelayan ke laut } \\
\text { mendengar kabar } \\
\text { seorang } \\
\end{array}$ & $\begin{array}{c}\text { Saat terjadi musibah pada } \\
\text { sesama kawan, para } \\
\text { nelayan saling membantu }\end{array}$ \\
\hline $\begin{array}{l}\text { Nelayan hilang di } \\
\text { lautan dan kembali } \\
\text { hanya perahu) }\end{array}$ & $\begin{array}{l}\text { Nelayan tidak memiliki } \\
\text { peralatan keamanan saat } \\
\text { terjadi musibah di lautan } \\
\text { sehngga merenggut } \\
\text { nyawa. }\end{array}$ \\
\hline
\end{tabular}

\begin{tabular}{|c|c|}
\hline $\begin{array}{c}\text { Nenek moyang seorang } \\
\text { pelaut }\end{array}$ & $\begin{array}{c}\text { Nenek moyang bangsa } \\
\text { Indonesia dikenal sebagai } \\
\text { pelaut }\end{array}$ \\
\hline $\begin{array}{c}\text { Gemar mengarungi luas } \\
\text { samudra }\end{array}$ & $\begin{array}{l}\text { Nenek moyang cinta } \\
\text { samudera dan gemar } \\
\text { berlayar }\end{array}$ \\
\hline $\begin{array}{c}\text { Menerjang ombak tiada } \\
\text { takut }\end{array}$ & $\begin{array}{c}\text { Nenek moyang berani } \\
\text { dan tidak kenal takut saat } \\
\text { di laut }\end{array}$ \\
\hline $\begin{array}{c}\text { Menempuh badai sudah } \\
\text { biasa }\end{array}$ & $\begin{array}{c}\text { Saat di lautan berbagai } \\
\text { tantangan ombak dan } \\
\text { badai sudah dianggap } \\
\text { biasa } \\
\end{array}$ \\
\hline Rentang jala pukat & $\begin{array}{l}\text { Peralatan nelayan yang } \\
\text { sederhana saat menangkap } \\
\text { ikan }\end{array}$ \\
\hline Tarik-tariklah tambang & $\begin{array}{c}\text { Peralatan menangkat ikan } \\
\text { yang mengandalkan } \\
\text { tenaga manusia semata }\end{array}$ \\
\hline $\begin{array}{l}\text { Kail dan jala cukup } \\
\text { menghidupimu }\end{array}$ & $\begin{array}{c}\text { Sebuah metafora dalam } \\
\text { menggambarkan } \\
\text { kemakmuran Indonesia } \\
\text { bahwa denga kail dan jala } \\
\text { dapat memenuhi } \\
\text { kebutuhan hidup sehari- } \\
\text { hari } \\
\end{array}$ \\
\hline $\begin{array}{l}\text { Bukan lautan hanya } \\
\text { kolam susu }\end{array}$ & $\begin{array}{c}\text { Lautan dianggap sebagai } \\
\text { sumber kehidupan }\end{array}$ \\
\hline $\begin{array}{c}\text { Selamat tinggal Teluk } \\
\text { Bayur permai }\end{array}$ & $\begin{array}{c}\text { Mengucapkan perpisahan } \\
\text { dengan tempat yang } \\
\text { dicintai, yakni Teluk } \\
\text { Bayur } \\
\end{array}$ \\
\hline $\begin{array}{l}\text { Bersama camar-camar } \\
\text { mengalunkan simponi }\end{array}$ & $\begin{array}{c}\text { Burung camar yang } \\
\text { beriring di atas laut lepas } \\
\text { bagai sebuah nyanyian } \\
\text { yang indah penuh } \\
\text { kedamaian } \\
\end{array}$ \\
\hline $\begin{array}{l}\text { Burung-burung putih } \\
\text { terbang jauh }\end{array}$ & $\begin{array}{l}\text { Burung camar sebagai } \\
\text { metafora kehidupan } \\
\text { manusia mencari nafkah }\end{array}$ \\
\hline $\begin{array}{c}\text { Buih laut seindah } \\
\text { bunga melati }\end{array}$ & $\begin{array}{l}\text { Mengibaratkan buih laut } \\
\text { dengan keindahan }\end{array}$ \\
\hline $\begin{array}{l}\text { Buih laut bagai tempat } \\
\text { mandi bidadari }\end{array}$ & $\begin{array}{c}\text { Laut bagaikan surgawi, } \\
\text { tempat mandi para } \\
\text { bidadari }\end{array}$ \\
\hline
\end{tabular}

Unsur penanda dan petanda pada syair lagu yang merepresentasikan budaya masyarakat yang hidup di kepulauan atau masyarakat maritim ditunjukkan oleh sign berupa kata benda (alat), seperti "kapal", "perahu", "perahu nelayan", perahu "bangsaku", "perahu layar" yang menjelaskan terhadap petanda sebagai sebuah peralatan utama bekerja pada masyarakat kepulauan. Penanda selanjutnya berupa kata benda yang diikuti dengan keterangan "perahu memecah ombak", "perahu berayun-ayun di lautan", "perahu tenggelam", "perahu menyusuri gelombang" yang memiliki relasi dengan aktivitas sebuah 
perahu sehari-hari di lautan. Petanda yang dihadirkan dari sign ini adalah perahu yang sederhana yang dimiliki oleh para nelayan mampu berlayar, menyusuri gelombang di tengah lautan, namun terombang ambing dan memungkinkan dapat tenggelam.

Beberapa penanda lain menunjukkan simbol peralatan saat melaut, seperti "jala", "jala pukat", "kail", "umpan", "tambang" yang menunjuk pada sebuah peralatan yang cukup sederhana untuk menangkap ikan di laut lepas. Kondisi ini menyiratkan makna betapa berat profesi nelayan untuk mencukupi kebutuhan ekonomi keluarga apabila hasil tangkapan yang didapat tidak sebanding dengan perjuangan yang dilakukan. Sistem tanda yang menunjuk pada kehidupan nelayan memprihatinkan tampak pada sign "nelayan tua", "nelayan sendiri mencari nafkah", "nelayan ditelan hiu", dan "nelayan hilang di lautan" dapat ditafsirkan sebagai seorang nelayan tua, sendiri mencari nafkah di lautan yang luas dan penuh tantangan, yang pada akhirnya nelayan tidak mampu menghadapi bencana di lautan, tenggelam dan ditelan hiu. Berbagai tantangan yang ada tidak menyurutkan semangat dan keberanian masayarakat untuk tetap memanfaatkan sumberdaya laut sebagai sumber kebutuhan hidup. Tanda-tanda kebahasaan ditunjukkan pada bentuk penanda "menerjang ombak tiada takut", "menempuh badai sudah biasa", dan "buih laut seindah bunga melati" yang dapat ditafsirkan bahwa seorang pelaut (nelayan) janganlah takut terhadap ombak dan badai karena hal ini sudah biasa terjadi serta buih-buih di laut dianggap sebagai sebuah keindahan dari warna kehidupan.

\subsection{Budaya Kemaritiman dalam Syair Lagu Kemaritiman}

Penanda budaya kemaritiman pada masyarakat Indonesia yang ditemukan dalam syair lagu yang dianalisis terdapat empat unsur, yakni berupa sistem mata pencaharian hidup, sistem peralatan hidup dan teknologi, sistem pengetahuan, dan sistem keorganisasian Masyarakat.

\section{Sistem Mata Pencaharian Hidup}

Terkait dengan pemenuhan konsumsi sehari-hari serta kebutuhan ekonomi keluarga, masyarakat pesisir mengandalkan mata pencahariannya sebagai nelayan. Mereka mengarungi samudra luas untuk mencari ikan atau sumber alam di lautan. Hal ini dilakukan oleh sebagian besar masyarakat yang sudah menjadi sumber utama kehidupannya dan bahkan diteruskan oleh anak keturunanya. Beberapa penanda dan petanda pada syair lagu berikut dapat dimaknai sebagai aktivitas masyarakat untuk memenuhi kebutuhan hidup.

\section{Dengarlah kisahku tentang nelayan tua \\ Di laut biru dia berlayar \\ Sendiri mencari nafkah di samudra \\ Terbalik tenggelam dimakan hiu}

(Nelayan Tua/Bimbo)

Nelayan, merupakan sebuah pekerjaan yang penuh tantangan dan berisiko tinggi. Mereka umumnya menyadari dan berusaha menjaga keselamatan diri, meskipun tragedi yang diakibatkan oleh alam tidak dapat dielakkan, seperti badai, gelombang, juga ikan buas seperti pada syair Nelayan Tua yang tewas tenggelam dan dimakan Hiu.

Meskipun penuh tantangan, masyarakat pesisir meneruskan aktivitas ekonomi dalam memenuhi kebutuhan ekonomi kepada anakanaknya. Peristiwa tragis pun menimpa nelayan muda yang hilang di lautan dan menyisakan kesedihan pada istri yang ditinggalkan. Hal ini tampak pada sign yang ditampilakn pada syair lagu Lenggak Lenggok Badai Lautku berikut.

Apakah yang terjadi aku tak tahu, Apakah yang terjadi hei di situ

Kiranya nelayan muda kembali hanya perahu

Meninggalkan istri lama bersedih

menunggu

(LLBL/Leo Kristi)

\section{Sistem Peralatan Hidup dan Teknologi}

Peralatan hidup utama masyarakat maritim atau pesisir adalah perahu atau 
kapal dan kelengkapannya. Perahu merupakan sarana transportasi di laut sekaligus sebagai alat kerja dalam memenuhi kebutuhan hidup sehari-hari. Sistem peralatan dan teknologi tidak jauh dari kebisaan perilaku hidup sehari-hari, khususnya dalam kelangsungan hidup,

Meskipun perahu merupakan alat utama dalam pemenuhan kebutuan hidup, namun tidak semua keluarga memilikinya. Para nelayan yang tidak memiliki perahu akan menyewa kepada pemilik perahu yang disewakan. Tidak semua nelayan memiliki kondisi ekonomi yang berkecukupan atau mapan. Sebaliknya, banyak para nelayan yang hidupnya memprihatinkan. Hal ini tergambarkan pada syair lagu 'Nelayan' yang dinyanyikan Iwan Fals berikut.

Perahu tunggakan KUD belum terbayar

Belum lagi tagihan rentenir seberang jalan

Nelayan kecil hasil kecil nasib pun kecil

Menjerat jala dihantam kerasnya gelombang

Perahu tunggakan KUD belum terbayar

Hitam hidup.... Hitam hidup

(Nelayan/ Iwan Fals)

Sistem peralatan dan teknologi para nelayan pun juga sederhana. Mereka menggunakan jala, pukat, tambang, untuk menangkap ikan. Kondisi inilah yang menjadikan tangkapan ikan para nelayan sedikit dan kadang juga tidak berhasil. Selain faktor peralatan yang mereka gunakan sederhana, juga kondisi alam yang tidak mendukung seperti ombak besar, badai dan topan. Penggambaran kondisi ini telah dinyatakan dalam sebuah tanda dalam penggalan syair lagu 'Tak Biru Lagi Lautku' dinyayikan oleh Iwan Fals dan Leo Kristi berikut.

Tampak ombak

Kejar-mengejar menuju karang

Menampar tubuh pencari ikan

(TBLL/Iwan Fals)
Lihat-lihat nelayan rentang jala pukat Tarik-tariklah tambang, umpan sudah lekat. (Ikannya melompat-lompat riang riaaang...

Jauh di kaki langit terbentang layarmu Kadang naik, kadang turun, dimainkan oleh ombak

Badai laut biru

(Gglg-Leo Kristi)

\section{Sistem Pengetahuan Masyarakat}

Masyarakat pesisir sangat memahami dan mengenal situasi dan kondisi lingkungan yang ditempati secara turun temurun, mulai dari cuaca, angin, laut dan kehidupan di dalamnya. Sistem pengetahuan masyarakat yang bersifat abstrak diwujudkan dalam bentuk konkrit seperti peralatan serta sikap dan tindakan untuk kelangsungan hidup. Wujud konkrit dari pengetahuan masyarakat pesisir berupa kemampuan membaca kondisi alam di lautan saat berlayar dan menyusuri gelombang. Nelayan melihat cakrawala membentang di depan mata dan menganggap tidak ada tantangan berarti yang perlu dicemaskan. Penanda ini tampak pada lagu 'Perahu Retak' berikut

\section{Perahu negeriku, perahu bangsaku}

Menyusuri gelombang

Semangat rakyatku, kibar benderaku

Menyeruak lautan

Langit membentang, cakrawala di depan

Melambaikan tantangan

(Perahu Retak/Franky Sahilatua)

Suatu masyarakat tidak akan sanggup membuat sesuatu yang dibutuhkan dalam kelangsungan hidupnya apabila tidak memiliki sekumpulan pengetahuan. Demikian halnya dengan pengetahuan membuat kail, jala, pukat, umpan, serta kondisi berkumpulnya ikan, serta pasang surut air. Jika hal ini dipahami maka lautan dapat diibaratkan sebagai "kolam susu", yakni sebuah wilayah yang subur, kaya, bermanfaat bagi kehidupan. Pengetahuan akan kekayaan dan kesuburan wilayah lautan dan daratan Indonesia ini penting 
dipahami masyarakat agar selanjutnya dapat menjaganya. Sebuah syair lagu 'Kolam Susu' merupakan metafora kesuburan dan kekayaan laut Indonesia.

\section{Bukan lautan hanya kolam susu \\ Kail dan jalan cukup menghidupimu \\ Tiada badai tiada topan kau temui \\ Ikan dan udang menghampiri dirimu}

(Kolam Susu/ Koes Plus)

Penanda (signifier) budaya sistem pengetahuan dalam membaca kondisi alam pada masyarakat maritim tampak pada syair lagu "Nenek Moyangku Seorang Pelaut". Pada syair lagu ini menggambarkan bahwa bangsa Indonesia sudah terbiasa mengarungi samudera, mengenal ombak, mengenal badai sehingga tidak takut melayar. Berikut syair lagu Nenek Moyangku.

\section{Nenek moyangku seorang pelaut gemar mengarung luas samudra menerjang ombak tiada takut menempuh badai sudah biasa}

\section{Sistem Keorganisasian Masyarakat}

Masyarakat pesisir yang hidup secara turun temurun di wilayah kepulauan tentunya mengenal baik situasi dan kondisi lingungan yang ada di sekitarnya. Antarindividu hidup bersama dan bergaul sesuai dengan aturan dan adat istiadat yang berlaku di lingkungannya. Hingga pada akhirnya mereka membentuk suatu masyarakat sosial dalam sebuah sistem kekerabatan dan keorganisasian yang disepakati bersama. Sistem sosial yang paling dekat adalah keluarga dan kerabat hingga kerabat yang lebih luas berdasarkan lokalitas geografis.

Bentuk penanda sistem sosial yang menggambarkan kebersamaan, keceriaan, keramaian dalam pergaulan terdapat pada sayair lagu "Tanjung Perak". Sebaliknya, sikap sosial berupa rasa duka dan empati digambarkan dalam sebuah metafora seribu burung camar berlayangan penuh duka serta laut sunyi suara. Berikut kedua syair lagu tersebut.

\author{
Ayo rame-rame di kota Tanjung Perak \\ Panggil satu taksi kita bersorak bersama \\ Tanjung Perak tepi laut \\ Siapa suka boleh ikut \\ Bawa gitar keroncong piul \\ Jangan lupa bawa anggur \\ Tanjung Perak.. tepi laut \\ (Tanjung Perak/Waljinah)
}

Burung camar seribu berlayangan

Mereka duka laut pun sunyi suara

Dengarlah kisahku tentang nelayan tua

Di laut biru dia berlayar

(Nelayan Tua/ Bimbo)

Sistem kekerabatan pada kelompok sosial juga ditampakkan oleh masyarakat nelayan saat mengetahui salah seorang nelayan, yakni seorang nelayan muda mengalami musibah saat melaut. Masyarakat berbondong-bondong ke laut untuk memastikan keberadaan anggota sosial yang hilang di laut dan hanya perahunya saja yang kembali. Hal ini tampak pada syair berikut.

\section{Hmmmm, berbondong-bondong nelayan ke laut \\ Apakah yang terjadi aku tak tahu, Apakah yang terjadi, hei di situ \\ Kiranya nelayan muda kembali hanya perahu}

(LLBL/Leo Kristi)

Bentuk penanda yang terdapat pada syair lagu kemaritiman berupa aspek material, yakni dapat diindera berupa "perahu”, "ombak", "badai", "perahu layar", "kail", "umpan", "nelayan tua". Jika dikaitkan dengan konsep Saussure, maka bentuk-bentuk tersebut baru sebatas wujud citra bunyi yang memiliki keterkaitan dengan konsep. Selanjutnya apabila penanda (signifier) tersebut dimaknai secara konseptual yang bersumber dari ideasional signnya, maka dapat ditentukan oleh kesepakatan masyarakat dalam memberikan penafsirannya. Jika hal ini yang terjadi maka pemaknaan terhadap sign tersebut bersifat aribtrer atau kesewenangan dari pemberian 
makna yang melekat pada penanda (Budiman, 1999). Makna arbitrer 'perahu layar', yakni sebagai suatu alat transportasi di laut atau sarana yang membantu nelayan mencari ikan dengan bentuk yang khas sebagai perahu dan ditambahakan layar agar dapat mengatur arah angin saat melaju. Sebaliknya, 'perahu' sebagai signifier akan memiliki makna konotasi apabila terdapat makna implisit dari ujaran yang diaktualisasikan, yakni bermakna "rumah kehidupan', 'nyawa keluarga', 'harapan masa depan'.

Dalam pandangan Barthes (2007), setiap tanda memiliki makna yang diawali dari makna denotasi. Selanjutnya makna konotasi tidak terlepas aspek emotif yang pada akhirnya akan melahirkan makna kedua atau sekunder sebagai bentuk ekspresi dari pemaknaan tanda. Dalam kajian kebudayaan pandangan barthes ini sangat relevam dalam mengungkapkan aspek kebudayan yang membangun kebiasaan atau sikap yang berlaku pada kelompok, termasuk dlam sistem budaya. Perahu sering digunakan sebagai simbol yang mewakili pada suatu konsep tertentu Hal ini berangkat pada suatu kiasan yang mereferensi signifier pada suatu hal yang berbeda. 'Perahu' melambangkan rumah bagi keluarga, kesejahteraan keluarga, ketercapaian harapan. Perahu pada masyarakat pesisir memiliki makna status sosial, tingkat kesejahteraan karena secara kultural masayarakat pesisir identik dengan kemiskinan dan kelompok marjinal. Hal ini akibat faktor strutural dal kultural yang membelit kehidupan mereka (Kristiyanti, 2016).

Sistem budaya yang terdapat dalam lagu-lagu kemaritiman yang dinyanyikan oleh Iwan Fals lebih menunjukkan sebuah metafora, yakni sebuah kiasan guna mengritik sikap pemimpin, sistem dalam pemerintahan yang ada, dan kemiskinan masyarakat. Lagu 'Nelayan' menggunakan tanda yang menggambarkan kemiskinan nelayan; nelayan terlilit hutang; nelayan berpenghasilan kecil; serta kerasnya kehidupan nelayan. Metafora yang digunakan tagihan rentenir, nelayan kecil, nasib kecil; perahu tunggakan KUD. Lagu Nelayan ingin menyampaikan pesan potret seorang nelayan miskin bekerja keras untuk anak istri dengan tagihan hutang sana-sini termasuk tunggakan perahu KUD. Makna denotasi sebagaimana penanda ekpresif yang dinyatakan oleh penciptanya, mengembangkan sistem sekunder pemaknaan yang dapat dikaitkan dengan aspek sosial kemasyarakatan yang terjadi. Latar penciptaan lagu sangat mendukung dalam pemahaman makna konotasi yang tidak hanya didasarkan pada aspek kognitif namun juga aspek pragmatik dalam pemakaian tanda dan situasi pemahamannya.

Fenomena kemiskinan pada masyarakat nelayan ini menjadi ciri khas (Pranowo \& Hidayatulloh, 2015). Kehidupan masyarakat nelayan yang miskin dapat dilihat dari keterbatasan pemilikan modal, keterbatasan memperoleh pendidikan, keterbatasan dalam pemeilikan alat tangkapan serta pemenuhan kebutuan dasar lainya, seperti tempat tinggal. Kemiskinan yang umum dirasakan oleh masyarakt pesisir mampu membentuk sikap kerjasama dan kepedulian. Budaya sosial dibentuk secara bersama dan universal dalam melahirkan nilai-nilai yang diwariskan (Husain \& Musfirah, 2020).

Budaya masyarakat maritim dilihat dari sistem mata pencaharian, sehari-hari beraktivitas yang terkait kehidupan pada laut, seperti mengelola hasil laut meskipun sifatnya terbatas serta melaut mencari ikan, udang, kepiting atau cumu-cumi (Pranowo \& Hidayatulloh, 2015). Untuk itu, sistem pengetahuan dan peralatan teknologi tidak jauh dengan aktivitas yang mereka lakukan sehari-hari (Kambey, 2020). Beberapa keterbatasan yang dimiliki masyarakat pesisir merupakan budaya yang tetap dipertahankan. Mereka melakukan aktivitas rutin sebagaimana budaya lokal yang biasa dikembangkan dan dijalani (Touwe, 2020). Untuk itu, sulit melakukan perubahan pada masayarakat pesisir terhadap hal-hal baru. 


\section{Kesimpulan}

Penanda budaya masyarakat maritim ditampilkan pada simbol benda materi yang digunakan sehari-hari, baik sebagai sistem mata pencaharian hidup, sistem peralatan hidup dan teknologi, sistem pengetahuan dan sistem keorganisasian kemasyarakatan. Syair lagu kemaritiman merepresentasikan budaya masyarakat pesisir melalui tanda yang bersifat arbitrer, baik yang bermakna konotasi dan denotasi.

Budaya kemaritiman yang tergambarkan pada syair lagu kemaritiman telah mewakili kehidupan masyarakat pesisir dengan ditunjukkan penanda pemenuhan hidup sehari-hari beserta peralatan yang digunakan. Pearalatan yang dimanfaatkan hasil pemahaman dari pengetahuan yang dimiliki untuk kelangsungan hidup. Sistem organisasi sosial terbangun kuat sebagai sebagai bentuk hubungan kekerabatan yang kuat. Petanda yang mewakili makna tanda yang merepresentasikan budaya masyarakat maritim meliputi tentang perjuangan hidup nelayan, kemiskinan masyarakat pesisir, semangat dan keberanian mengarungi samudera, kesuburan dan kekayaan sumber alam laut, serta keindahan panorama alam di wilayah pesisir. Masyarakat pesisir sangat menyatu dengan alam dan memiliki jiwa tangguh menghadapi segala tantangan dan rintangan. Komitmen ini hendaknya tetap terjaga dan berupaya mengembangkan diri agar dapat memanfaatkan potensi kekayaan laut secara maksimal untuk meningkatkan taraf kesejahteraan hidup.

\section{Ucapan Terima Kasih}

Terima kasih kepada pimpinan Universitas Muhammadiyah Malang, bapak rektor dan jajaran para wakilnya yang telah memberikan fasilitas dalam pelaksanaan penelitian. Terima kasih juga kepada DPPM Universitas Muhammadiyah Malang yang telah mendukung dan memfasilitasi secara teknis penelitian, kepada pimpinan Fakultas Keguruan dan Ilmu Pendidikan serta Program Studi Pendidikan Bahasa Indonesia.

\section{Daftar Pustaka}

Barthes, R. (2007). Membedah Mitos-Mitos Budaya Massa: Semiotika atau Sosiologi Tanda, Simbol dan Representasi. Bandung: Jalasutra. http://library.fis.uny.ac.id/opac/inde x.php?p=show_detail\&id=7919

Budiman, K. (1999). Kosa Semiotika. LkiS

Creswell, J. W. (2010). Research Design: Pendekatan Kualitatif, Kuantitatif, dan Mixed. Pustaka Pelajar

Darmoko, D. (2019). Revitalisasi Teks-Teks Kearifan Lokal Kemaritiman Untuk Membangun Kehidupan Bermasyarakat, Berbangsa, dan Bernegara. Pustaka: Jurnal IlmuIlmu Budaya, 19(1), 1-8. https://doi.org/10.24843/PJIIB.2019. v19.i01.p01

Dewi, N. M. P., Damayanti, S., Budiana, I, M. (2018). Semiotika dalam Lagu Che.r.ry dan Summer Song Karya Yui Yoshioka. Humanis: Journal of Arts and Humanities, 22(4), 904910.

https://doi.org/10.24843/JH.2018.v2 2.i04.p10

Fanani, F. (2013). Semiotika Strukturalisme Saussure. Jurnal The Messenger, 5 (1), $10-15$. http://dx.doi.org/10.26623/themesse nger.v5i1.149

Fuad, M. A. Z., \& Musa, M. (2017). Pengenalan Bidang Kemaritiman Sejak Usia Dini melalui Pembelajaran Tematik Kelautan pada Siswa Taman Kanak Kanak. Jurnal Pendidikan Geografi: Kajian, Teori, dan Praktek dalam Bidang Pendidikan dan Ilmu Geografi, 22 (2), 93-104. http://dx.doi.org/10.17977/um017v2 2i22017p093

Hairudin, H., \& Wahyuni, S. (2019). Sistem Pengetahuan Masyarakat Nelayan 
Pesisir Pulau Kasu Kecamatan Belakang Padang Kota Batam. Jurnal Masyarakat Maritim, 3(2), 50-64.

https://doi.org/10.31629/jmm.v3i2.1 721

Hamka. (1962). Tenggelamnya Kapal Van der Vijk. Jakarta: Penerbit Nusantara.

Harnia, N. T. (2021). Analisis Semiotika Makna Cinta pada Lirik Lagu "Tak Sekedar Cinta" Karya Dnanda. Jurnal Metamorfosa, 9(2), 224-238. https://doi.org/10.46244/metamorfos a.v9i2.1405

Harnoko, D. (2016). Bunga Rampai Lawatan Sejarah Regional: Menelusuri Jejak Sejarah Maritim Di Pantai Utara Jawa Tengah. Kementerian Pendidikan dan Kebudayaan Direktorat Jenderal Kebudayaan Balai Pelestarian Nilai Budaya (Bpnb) Daerah Istimewa Yogyakarta.

http://repositori.kemdikbud.go.id/11 42/1/bunga\%20rampai\%20komplit. pdf

Haryadi, T. (2016). Analisis Iklan Televisi Sampoerna Hijau Versi "Es Kacang Ijo" dengan Pendekatan Semiotika Roland Barthes. Jadecs, 1(1), 1-16. http://dx.doi.org/10.17977/um037v1 i12016p\%25p

Husain, N. F., Dj, M. Z., \& Musfirah, M. (2020). Semiotic Analysis to The Cultural Content in The Efl Textbook. IJRETAL: International Journal of Research on English Teaching and Applied Linguistics, $1(2)$, 67-82. http://dx.doi.org/10.30863/ijretal.v1i 2.1230

Imron, D. Z. (2000). Bantalku Ombak Selimutku Angin. Yogyakarta: Gama Media.
Ismail, H. A., \& Kartika, E. (2019). Peran kemaritiman Indonesia di Mata Dunia. Jurnal Sains dan Teknologi Maritim, 20(1), 83-89. http://dx.doi.org/10.33556/jstm.v20i 1.222

Janawi, J. (2018). Geneologi Suku Laut Bangka Belitung. Tawshiyah, 13(2), $1-28$.

https://doi.org/10.32923/taw.v13i2.1 166

Juwana, H. (2003). Putusan MI atas Pulau Sipadan dan Ligitan. Indonesian Journal of International Law, 1(1), 169-

182. http://dx.doi.org/10.17304/ijil. vol1.1.510

Kambey, M. A., Aling, D. R. R., \& Dien, C. R. (2020). Eksistensi Budaya Maritim Kelompok Nelayan Kelurahan Malalayang Dua, Kota Manado, Provinsi Sulawesi Utara. Akulturasi:_Jurnal Ilmiah Agrobisnis Perikanan, 8(1), 136146 ,

https://doi.org/10.35800/akulturasi.8 .1.2020.28979

Kristiyanti, M. (2016). Pemberdayaan Masyarakat Pesisir Pantai melalui Pendekatan ICZM (Integrated Coastal Zone Management). Prosiding Seminar Nasional Multi Disiplin Ilmu \& Call For Papers Unisbank (Sendi_U) Ke-2, 2016 "Kajian Multi Disiplin Ilmu dalam Pengembangan IPTEKS untuk Mewujudkan Pembangunan Nasional Semesta Berencan (PNSB) sebagai Upaya Meningkatkan Daya Saing Global". https://www.unisbank.ac.id/ojs/inde x.php/sendi_u/article/view/4264

Kementerian Koordinator Bidang Kemaritiman. (2020). Salinan Peraturan Menteri Koordinator Bidang Kemaritiman dan Investasi RI Nomor 6 Tahun 2020 Tentang 
Rencana Strategis Kementerian Koordinator Bidang Kemaritiman dan Investasi Tahun 2020 - 2024. https://jdih.maritim.go.id/en/peratur an-menteri-koordinator-bidangkemaritiman-dan-investasi-no-6tahun-2020

Kurniawati, A. (2017). Peran Istri Nelayan dalam Rangka Meningkatkan Pendapatan Keluarga. Jurnal Sains Dan Teknologi Maritim, 17(1), 7788 ,

http://dx.doi.org/10.33556/jstm.v0i1 .160

Kusumawati, H. (2013). Pendidikan Karakter Melalui Lagu Anak-Anak. Imaji: Jurnal Seni dan Pendidikan Seni, 11(2), 1-11, https://doi.org/10.21831/imaji.v11i2 .3839

Marseto, M. (2018). Kedaulatan Maritim di Nangroe Aceh Darussalam: Perpektif Budaya dan Pariwisata. Bogor: Universitas Pertahanan Kawasan IPSC. http://opac.lib.idu.ac.id/unhanebook/assets/uploads/files/6e048kedaulatan-maritim-di-nangroe-danpariwisata.pdf

Oktavianus, O. (2019). Bahasa dan Budaya Maritim: Identitas dan Pemerkaya Budaya Bangsa. Pustaka: Jurnal Ilmu Ilmu Budaya, 19(1), 17-22, https://doi.org/10.24843/PJIIB.2019. v19.101.p04

Pasaribu, R. B. F. (2015). Kebudayaan dan masyarakat. http://eprints.dinus.ac.id/14516/1/\% 5BMateri\%5D_Bab_04_kebudayaa n_dan_masyarakat.pdf

Pranowo, P., \& Hidayatulloh, A. N. (2015). Perspektif dan Dinamika Nelayan terhadap Usaha Kesejahteraan Sosial. Jurnal Penelitian Kesejahteraan Sosial, 14(1), 94-106, https://ejournal3.kemsos.go.id/index .php/jpks/issue/view/138
Rahardja, S. (2018). Warisan Budaya Maritim Nusantara. Direktorat Jenderal Kebudayaan Direktorat Pelestraian Cagar Budaya dan Permuseuman.

http://perpusbalarjogja.kemdikbud.g o.id/index.php?p=show_detail\&id=1 1880\&keywords $=$

Rencana Strategis Kementerian Koordinator Bidang Kemaritiman dan Investasi Tahun 2020-2024. (2020). https://maritim.go.id/rencanastrategis-kementerian-koordinatorbidang-kemaritiman/ Diakses pada tanggal 10 September 2021.

Salinan Peraturan Menteri Koordinator Bidang Kemaritiman dan Investasi Republik Indonesia Nomor 6 Tahun 2020 Tentang Rencana Strategis Kementerian Koordinator Bidang Kemaritiman dan Investasi Tahun $2020 \quad-\quad 2024$. https://maritim.go.id/konten/unggah an/2020/06/ND-PenyampaianPermenko-Renstra-Internal.pdf

Sobur, A. (2002). Bercengkerama dengan Semiotika. Mediator, 3(1), 31-50, https://doi.org/10.29313/mediator.v3 i1.746

Sobur, A. (2009). Semiotika Komunikasi. Rosdakarya

Sudjiman, P., \& Van Zoest, A (Ed.). (1996). Serba-serbi Semiotik. PT Gramedia Pustaka Utama

Sumarto, S. (2019). Budaya, Pemahaman dan Penerapannya: Aspek Sistem Religi, Bahasa, Pengetahuan, Sosial, Keseninan dan Teknologi. Jurnal Literasiologi, 1(2), 144-159, https://doi.org/10.47783/literasiologi .$v 1 \mathrm{i} 2.49$

Syawaludin, M. (2017). Teori Sosial Budaya dan Methodenstreit. Palembang: Amanah. 
Toer, P. A. (1987). Gadis Pantai. Ebook, http://www.rakyatmembaca.com/20 19/04/ebook-gadis-pantaipramoedya-ananta-toer.html

Toer, P. A. (1995). Arus Balik. Ebook, https://tabloidsastra.files.wordpress. com/2015/02/arus-balik-_pramoedya-ananta-toer.pdf

Touwe, S. (2020). Local Wisdom Values of Maritime Community in Preserving Marine Resources in Indonesia. Journal of Maritime Studies and National Integration, 4(2), 84-94. https://ejournal2.undip.ac.id/index.p hp/jmsni/article/view/4812

Udu, S. (2017). Wowine dalam Kebudayaan Matirim Wakatobi Buton: Analisis Pierre Bourdieu. SASDAYA, Gadjah Mada Journal of Humanities, 2(1), 267-282.

https://garuda.ristekbrin.go.id/docu ments/detail/999958

Wahid, A. (2018). Pusaka Sejarah Maritim Di Indonesia: Khasanah, Tantangan, dan Strategi Perlindungannya. Patrawidya, 19(1), 19-34, https://doi.org/10.52829/pw.92
Wasono, S. (2017). Potret Kehidupan Masyarakat Nelayan di Madura Dalam Kumpulan Cerpen Karapan Laut Karya Mahwi Air Tawar. Pusat, Majalah Sastra: Sastra Kemaritiman https://badanbahasa.kemdikbud.go.i d/lamanbahasa/sites/default/files/Ma jalah\%20Pusat\%20Edisi\%2012.pdf

Wibowo, W. (2017). Kemaritiman Indonesia: Sebuah Kajian Kritis Indonesian Maritime: A Critical Study. Jurnal Manajemen Transportasi Logistik, 4(2), 211-222, http://dx.doi.org/10.25292/j.mtl.v4i2 .75

Wiradharma, G., \& Yusar, N. I. (2017). Kearifan Budaya dalam Lirik Lagu Melayu. Arkhais, 8(1), 1-11, https://doi.org/10.21009/ARKHAIS. 081.06 